\title{
Epigenetic modulation of PTEN expression during antiandrogenic therapies in human prostate cancer
}

\author{
GIOVANNI LUCA GRAVINA ${ }^{1,2}$, LEDA BIORDI ${ }^{4}$, FRANCESCO MARTELLA ${ }^{3}$, \\ VINCENZO FLATI ${ }^{4}$, ENRICO RICEVUTO ${ }^{3}$, CORRADO FICORELLA ${ }^{3}$, \\ VINCENZO TOMBOLINI ${ }^{1,2}$ and CLAUDIO FESTUCCIA ${ }^{2}$
}

\author{
${ }^{1}$ Department of Experimental Medicine, Division of Radiotherapy, ${ }^{2}$ Radiobiology Laboratory \\ Department of Experimental Medicine; ${ }^{3}$ Department of Experimental Medicine, Division of Oncology; \\ ${ }^{4}$ Department of Experimental Medicine, University of L'Aquila, L'Aquila, Italy
}

Received March 11, 2009; Accepted May 15, 2009

DOI: 10.3892/ijo_00000429

\begin{abstract}
Although the tumor-suppressor phosphatase and tensin homolog deleted on chromosome 10 (PTEN) is frequently mutated or deleted in a wide variety of solid tumors, some malignancies, including prostate cancer, exhibit undetectable PTEN protein without loss of PTEN gene. Aim of this study was to evaluate whether the PTEN downmodulation, observed during bicalutamide treatment, was due to epigentic events. We analyzed the expression of PTEN in presence or absence of azacitidine or valproic acid in a panel of 50 primary cultures derived from naive (UNT, $23 \mathrm{ptz}$ ) and bicalutamide-based neoadjuvant hormone therapy-treated patients (NHT, 27 pts). Results showed that Western blot and PCR analyses showed that 54 and $68 \%$ of primary cultures displayed detectable amounts of PTEN protein and mRNA, respectively. Treatment with azacitidine increased the percentage of PTEN-positive cultures up to 72 and $80 \%$ for PTEN protein and mRNA determination, respectively. Treatment with valproic acid was able to increase the percentage of PTEN-positive cultures up to 80 and $74 \%$ for PTEN protein and mRNA determination, respectively. The percentage of cultures with undetectable levels of PTEN protein was significatively higher in cultures derived NHT patients respect to cultures derived from UNT men $(\mathrm{P}=0.020)$. Valproic acid reduced significantly the percentage of cultures PTEN-negative only at protein level and only in NHT $(\mathrm{P}=0.029)$ group. In conclusion, our data suggests that antiandrogenic therapy reduced PTEN expression by epigenetic mechanisms suggesting that epigenetic drugs, upmodulating PTEN expression, can reduce Akt activity and probably enhance the efficacy of antiandrogenic therapy.
\end{abstract}

Correspondence to: Dr Claudio Festuccia, Department of Experimental Medicine, Radiobiology Laboratory, University of L'Aquila, Via Vetoio, Coppito 2, 67100 L'Aquila, Italy

E-mail: claudio.festuccia@univaq.it

Key words: prostate cancer, drug resistance, PTEN, PI3K, Akt

\section{Introduction}

Bicalutamide monotherapy at $150 \mathrm{mg} /$ day has been investigated as an alternative treatment for locally advanced prostate cancer (PC), based on its comparative benefits for quality of life issues and associated morbidity (1). However, many patients eventually progress to hormone-refractory status and require second-line therapies. Knowledge of molecular changes induced by the primary therapy may be informative in the selection and predicted success of subsequent therapies. Mutations and the loss of the tumor-suppressor phosphatase and tensin homolog deleted on chromosome 10 (PTEN) leads to constitutive activation of the Akt pathway, providing a mechanism whereby prostate tumor cells survive after the withdrawal of exogenous trophic factors or androgens, because activated Akt inhibits PC cell suicide (2,3). High PTEN is the most frequently mutated tumor-suppressor gene in PCa (3), where deletions, point mutations, and DNA methylation are reported to occur. Studies have shown that mice heterozygous for PTEN develop spontaneous tumors (4-8), and that conventional heterozygous Pten deletion leads to tumors in the affected tissues $(4,5,9-11)$. In addition, conditional deletion of both alleles of Pten significantly reduces the latency of prostate intraepithelial neoplasia (PIN) lesion development and further progression to localized adenocarcinoma followed by metastasis (4-6). Therefore, the onset and progression of prostate cancer are PTEN dosagedependent (4).

Similar to the majority of human prostate cancers, Pten null murine prostate cancer initially regress in response to androgen ablation therapy, but subsequently relapse and proliferate in the absence of androgens $(5,12,13)$. In addition, it has been demonstrated that the overexpression of PTEN in PTEN-negative PC3 cells by transfection reduces cell proliferation and increases the pro-apoptotic effects of chemotherapic agents $(14,15)$. In humans, this tumorsuppressor gene results inactivated in $\sim 30 \%$ of primary prostate cancers and in $\sim 60 \%$ of metastatic prostate tumors (16-20). The results showed by Bedolla and cooworkers indicate that, although PTEN by itself is not a good predictor of PSA recurrence, loss of PTEN expression, in combination with increased Gleason scores and Akt phosphorylation, is an 
even better predictor of biochemical recurrence than Akt by itself (21). In addition El Sheikh and cooworkers (22) demonstrated that patients negative for PTEN and AR had a poor prognosis respect to patients positive for both markers. Results from several in vitro studies using established $\mathrm{PCa}$ cell lines have demonstrated that PTEN and Akt are, respectively, negative and positive modulators of AR transcriptional activity (6, reviewed in ref. 23). Under experimental conditions, PTEN and AR exert opposite effects on cell growth and apoptosis.

We previously demonstrated that the in vivo androgen ablation therapy can reinforce the PI3K/Akt pathway through several mechanisms including the increased PTEN loss and EGFR/Her2 increased expression/activity (24). Activated Akt, in turn, mediates antiapoptotic signalling through the inactivation of a multitude of downstream targets involved in apoptosis regulation. Blockade of the PI3K/Akt pathway leads to apoptosis of PTEN-deficient cancer cells (24-26). Consequently, the PI3K/Akt pathway is currently a major therapeutic target (26) for treatment of cancer.

Interestingly, some malignancies exhibit undetectable PTEN protein without mutations or loss of PTEN mRNA. The cause(s) for this reduction in PTEN is unknown. To understand the mechanisms of PTEN loss we analyzed the expression levels of PTEN in a panel of 50 prostate cancer primary cultures. Our results indicated that PTEN inactivation is both a genetic (mutations or PTEN gene deletion) and an epigenetic (gene methylation and protein ubiquitinization and degradation) event. The first seems to be independent to antiandrogenic therapy whereas the second is increased after antiandrogenic therapy.

\section{Materials and methods}

Reagents and cell lines. All the materials for tissue culture were purchased from Hyclone (Cramlington, NE, USA). Plasticware was obtained from Nunc (Roskilde, Denmark). Azacitidine (Vidaza ${ }^{\circledR}$ ) was obtained in collaboration with Celgene Corporation (Summit, NJ, USA). Valproic acid, R1130 and 17AAG, were purchased from Sigma-Aldrich (St. Louis, MO, USA). Antibodies against PTEN, Akt and phosphor Akt were purchased from Santa Cruz (Santa Cruz, CA, USA). Anti-DNMT1, DNMT3a and DNMT3b antibodies were purchased from Biocarta (Hamburg, Germany). We used the aggressive prostate cancer model, 22rv1 (27) which was obtained from German Collection of Microorganisms and Cell Cultures (DSMZ, Braunschweig, Germany) and grown as recommended.

Primary tumor cultures. The primary tumor cultures of $\mathrm{PCa}$ were established from specimens of consenting patients undergoing radical prostatectomy. A wedge-shaped specimen of the fresh prostate was removed within $1 \mathrm{~h}$ of surgery. Frozen sections of a part of this tissue were used to confirm the prostatic origin and for diagnosis. We analysed a 50-patient cohort with clinically localized tumors that were surgically treated with RP as described $(24,28)$. Among these, 23 patients received $\mathrm{RP}$ as initial treatment, whereas the other 27 patients received NHT for 4 months based on casodex treatment. Tissue samples were minced and cultured in DMEM as previously described (29).
Growth assay. For pharmacological treatments, primary cultures and cell lines were seeded at a density of $2 \times 10^{4}$ cells per dish in $50 \mathrm{~mm}$ petri dishes. Cells were left to attach and grow in 5\% FCS DMEM for $24 \mathrm{~h}$. All other cells were treated with 1.0 or $10.0 \mu \mathrm{M}$ bicalutamide or $10^{-12} \mathrm{M}$ DHT. Cells trypsinized and resuspended in $20 \mathrm{ml}$ saline were counted by a hemocytometer every $48 \mathrm{~h}$ (LabRecyclers, Gaithersburg, MD, USA) and 5 independent counts were performed for each dish. All experiments were conducted in triplicate.

Apoptosis. Apoptosis was quantified as the percentage of cells with hypodiploid DNA assessed using HT titer TACS assay kit, a colorimetric quantitative assay for the detection of apoptosis (Trevigen, Gaithersburg, MD).

Preparation of cell lysates and Western blot analysis. Cells were seeded in 24-well tissue culture plates (Costar, Corning, NY) at 20,000 cells per well. At $24 \mathrm{~h}$ after seeding, cells were treated with azacitidine (final concentration of $1.0 \mathrm{mM}$ ). After $72 \mathrm{~h}$ of drug exposure, cells were washed with cold PBS and immediately lysed with $1 \mathrm{ml}$ lysis buffer (50 mM HEPES, pH 7.5, $150 \mathrm{mM} \mathrm{NaCl}, 10 \%$ glycerol, $1 \%$ Triton X-100, 1 mM EDTA, 1 mM EGTA, 50 mM NaF, 1 mM sodium orthovanadate, $30 \mathrm{mM}$ p-nitrophenyl phosphate, $10 \mathrm{mM}$ sodium pyrophosphate, $1 \mathrm{mM}$ phenylmethylsulfonyl fluoride, $10 \mu \mathrm{g} / \mathrm{ml}$ aprotinin and $10 \mu \mathrm{g} / \mathrm{ml}$ leupeptin). Lysates were electrophoresed in SDS-PAGE, and separated proteins transferred to nitrocellulose and probed with the appropriate antibodies using the conditions recommended by the suppliers.

RT-PCR for PTEN expression. Total RNA was extracted from cells with TRIzol reagent according to the manufacturer's instruction. An RT-PCR was carried out on Dnase Amp Grade (Gibco-BRL)-treated RNA using MuLV RT (50 units) in $100 \mathrm{mM}$ Tris- $\mathrm{HCl} \mathrm{pH} 8.3,500 \mathrm{mM} \mathrm{KCl,} 5 \mathrm{mM}$ $\mathrm{MgCl}_{2}, 0.5 \mu \mathrm{M}$ each dNTP, 1 unit of RNasin, 500 pmol of random examer primers. Two microliters of cDNA were amplified in a $50 \mu 1$ reaction volume containing $0.5 \mu \mathrm{M}$ of sense and antisense primers, 2.5 units of TaqDNA polymerase (Applied Biosystems, Milan, Italy), $200 \mu \mathrm{M}$ each $\mathrm{dNTP}$ and $1.5 \mathrm{mM} \mathrm{MgCl}$. A co-amplification of GAPDH was performed. Primers sequences used for PCR were: PTEN 3th exon Fw 5'-ATATTCTCTGAAAAGCTCTGG-3', PTEN Rev 5'-TTAATCGGTTTAGGAATCAA-3', GAPDH Fw 5'-CACCATGGAGAAAGGCCGGGG-3' and GAPDH Rev 5'-GACGGACACATTGGGGGTAG-3'. After amplification, $20 \mu 1$ of the PCR reaction mixture was analysed by $1.2 \%$ agarose gel electrophoresis and stained with ethidium bromide.

Statistical analysis. Statistical analysis was performed using SPSS 11.0 (SPSS, Inc., Chicago, IL) software. All P-values $<0.05$ were considered to indicate significance. All statistical tests were two-tailed. Continuous variables were analyzed using a unpaired Student's t-test. Differences among categorical variables were compared with Chi-square test. When multiple comparisons were performed the Tukey test was used. 
A

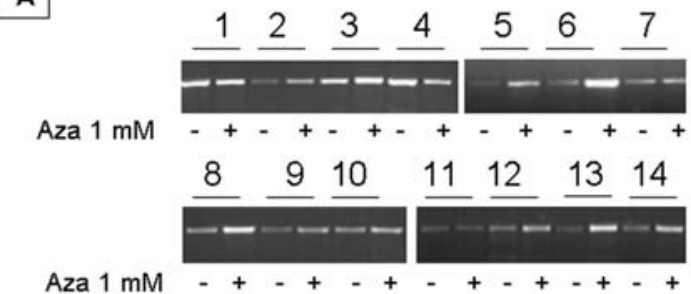

B $\begin{array}{llllllllllll}1 & 2 & 3 & 4 & 5 & 6 & 7 & 8 & 9 & 10 & 11 & 12\end{array}$

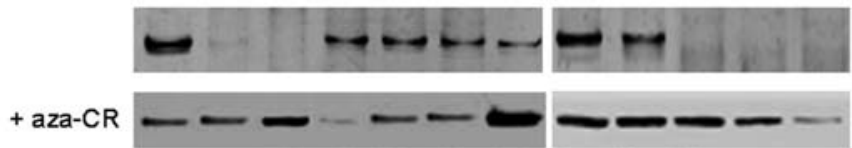

$131415 \quad 16 \quad 17 \quad 18 \quad 19 \quad 20$

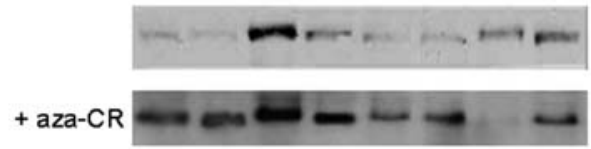

C

$\begin{array}{lcc}\text { Cultures } & \text { PTEN mRNA + } & \text { PTEN protein + } \\ \text { - Aza } & 34 / 50(68 \%) & 27 / 50(54 \%) \\ & & 36 / 50(72 \%) \\ \text { + Aza } & 40 / 50(80 \%) & P=0.098(\mathrm{NS})\end{array}$

Figure 1. Expression of PTEN mRNA (A) and protein (B) in representative primary prostate cancer cultures and role of azacitidine (Aza-CR) in the modulation of PTEN expression. (A) For mRNA analysises total RNA was extracted from cells with TRIzol reagent. Two microliters of cDNA were amplified in a $50 \mu 1$ reaction volume containing $0.5 \mu \mathrm{M}$ of sense and antisense primers, 2.5 units of Taq DNA polymerase, $200 \mu \mathrm{M}$ each dNTP and $1.5 \mathrm{mM} \mathrm{MgCl}$. After amplification, $20 \mu 1$ of the PCR reaction mixture was analysed by $1.2 \%$ agarose gel electrophoresis and stained with ethidium bromide. (B) Cells were seeded in 24-well tissue culture plates at 20,000 cells per well. At $24 \mathrm{~h}$ after seeding, cells were treated with azacitidine (final concentration of $1.0 \mathrm{mM}$ ). After $72 \mathrm{~h}$ of drug exposure, cells were washed with cold PBS and immediately lysed with $1 \mathrm{ml}$ lysis buffer. Lysates were electrophoresed in SDS-PAGE, and separated proteins transferred to nitrocellulose and probed with the appropriate antibodies using the conditions recommended by the suppliers. Each lane show the PTEN protein expression from $40 \mu \mathrm{g}$ of protein. (C) Summary of cultures positive for PTEN mRNA and protein, respectively.

\section{Results}

PTEN expression and effects of the DNA methyltransferase inhibitor, azacitidine. We analyzed the expression levels of PTEN, both as protein and mRNA, in a panel of 50 prostate cancer primary cultures. We observed that $27 / 50(54 \%)$ and $34 / 50(68 \%)$ primary cultures displayed detectable levels of PTEN protein and mRNA, respectively. After treatment with $1 \mathrm{mM}$ azacitidine for $48 \mathrm{~h}$, although PTEN protein expression was significantly increased in all PTEN-positive cultures, $14 / 23(60.7 \%)$ cultures with low levels of PTEN protein and $10 / 16(62.5 \%)$ cultures with low/undetectable mRNA levels resulted once again PTEN-negative. In Fig. 1A and B we show the effects of azacitidine $1 \mathrm{mM}$ in representative cultures: $14 / 50(28 \%)$ and $10 / 50(20 \%)$ of primary cultures were again PTEN-negative for protein and mRNA expression, respectively.

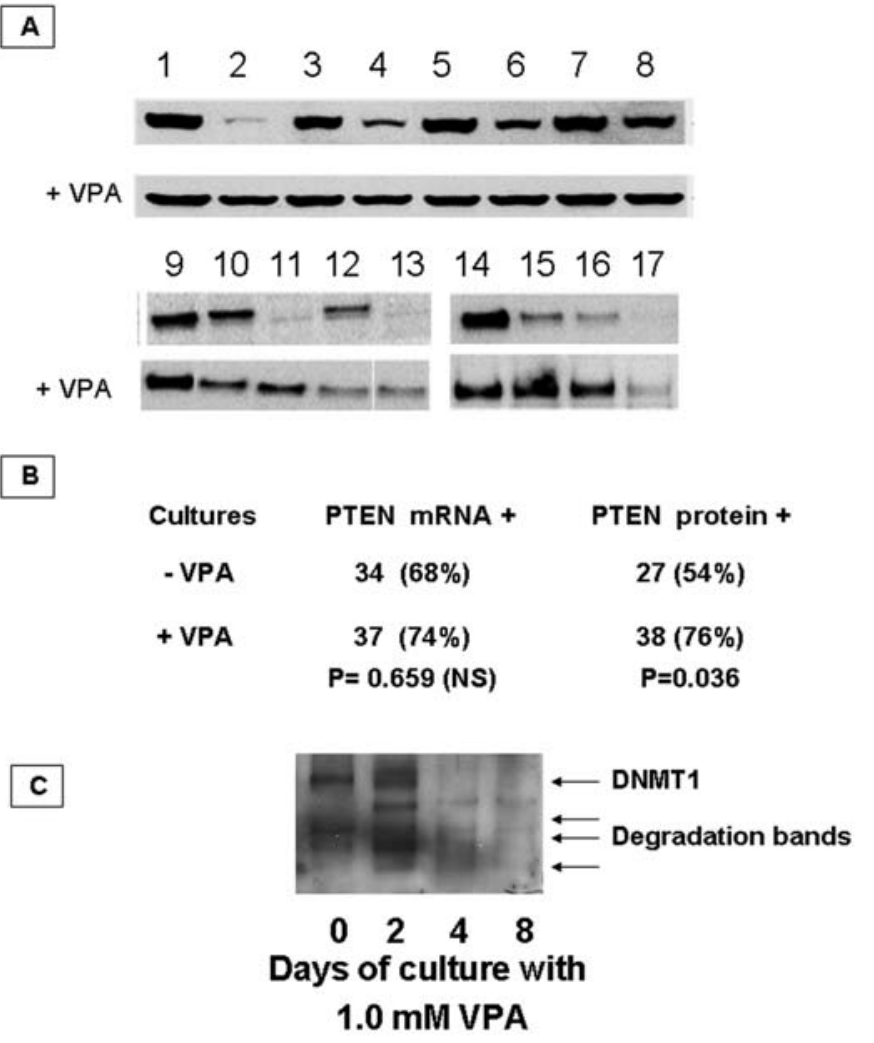

Figure 2. Effect of 1.0 mM of VPA on PTEN protein expression and role of DNMT1 downmodulation in the increased expression of PTEN protein levels by VPA. (A) representative PTEN expression with or without VPA in 17 primary cultures of prostate cancer. Cells were seeded in 24-well tissue culture plates at 20,000 cells per well. At $24 \mathrm{~h}$ after seeding, cells were treated with VPA (final concentration of $1.0 \mathrm{mM}$ ). After $72 \mathrm{~h}$ of drug exposure, cells were washed with cold PBS and immediately lysed with $1 \mathrm{ml}$ lysis buffer. Lysates were electrophoresed in SDS-PAGE, and separated proteins transferred to nitrocellulose and probed with the appropriate antibodies using the conditions recommended by the suppliers. Each lane show the PTEN protein expression from $40 \mu \mathrm{g}$ of protein. (B) Summary of cultures positive for PTEN mRNA and protein, respectively. (C) Effect of VPA on DNMT1 downmodulation and degradation in the time. Each lane show DNMT1 expression from $40 \mu \mathrm{g}$ of protein.

Effects of the pan histone deacethylase inhibitor, valproic acid. Considering that in addition to DNA methylation, also histone modifications are involved in gene expression we evaluated the effects of non-toxic concentration of the histone deacetyltransferase inhibitor, valproic acid (VPA, $1 \mathrm{mM}$ ) for $48 \mathrm{~h}$. We observed that this treatment increased PTEN protein expression. In Fig. 2A we show the effects of VPA $1 \mathrm{mM}$ in representative cultures. We observed that VPA increased PTEN expression (Fig. 2B). The effects of VPA were statistically significant only when we consider protein determinations $(\mathrm{P}=0.036)$. Further we observed that the treatment with $1 \mathrm{mM}$ VPA decreased the expression and increased the degradation of DNMT1 in all cultures. No changes in DNMT3a and DNMT3b expression were observed (data not shown). In Fig. 2C we show the time-dependent effect in a representative primary culture. Since pan HDAC inhibition with VPA could increased HDAC-6/HSP90- and proteasomedependent PTEN degradation we analyzed the effects of the proteasome inhibitor, MG132 $(1.0 \mu \mathrm{M})$ and HSP90 inhibitor, $\mathrm{R} 1130(0.1 \mu \mathrm{M})$. We demonstrated that these agents was able 


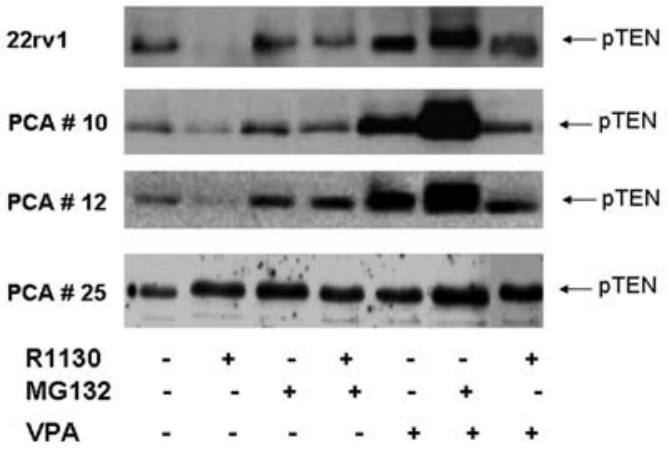

Figure 3. Effects of $0.1 \mu \mathrm{M}$ R1130 (HSP-90 inhibitor), $1.0 \mu \mathrm{M}$ MG132 (proteasome inhibitor) alone or in combination with $1.0 \mathrm{mM}$ VPA on three representative primary cultures and in 22rv1 cell line. Cells were seeded in 24-well tissue culture plates at 20,000 cells per well. At $24 \mathrm{~h}$ after seeding, cells were treated with VPA alone or in combination with R1130 or MG132. After $72 \mathrm{~h}$ of drug exposure, cells were washed with cold PBS and immediately lysed with $1 \mathrm{ml}$ lysis buffer. Lysates were electrophoresed in SDS-PAGE, and separated proteins transferred to nitrocellulose and probed with the appropriate antibodies using the conditions recommended by the suppliers. Each lane show the PTEN protein expression from $40 \mu \mathrm{g}$ of protein.

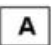

\begin{tabular}{|c|c|c|c|c|c|c|}
\hline \multirow{2}{*}{} & \multicolumn{2}{|c|}{$\begin{array}{c}\text { PTEN mRNA } \\
\text { positive }\end{array}$} & & \multicolumn{2}{c|}{$\begin{array}{c}\text { PTEN protein } \\
\text { positive }\end{array}$} & \\
\cline { 2 - 7 } & -Aza & +Aza & $\begin{array}{c}P \\
\text { value }\end{array}$ & -Aza & +Aza & $\begin{array}{c}\text { P } \\
\text { value }\end{array}$ \\
\hline UNT & $18 / 23$ & $21 / 23$ & 0.412 & $17 / 23$ & $19 / 23$ & 0.721 \\
& $(79.3 \%)$ & $(91.3 \%)$ & NS & $(73.9 \%)$ & $(82.6 \%)$ & NS \\
\hline NHT & $16 / 27$ & $19 / 27$ & 0.569 & $10 / 27$ & $17 / 27$ & 0.102 \\
& $(59.3 \%)$ & $(80.4 \%)$ & NS & $(37 \%)$ & $(63 \%)$ & NS \\
\hline $\begin{array}{c}P \\
\text { value }\end{array}$ & $\begin{array}{c}0.258 \\
\text { NS }\end{array}$ & $\begin{array}{c}0.136 \\
\text { NS }\end{array}$ & & 0.020 & $\begin{array}{c}0.220 \\
\text { NS }\end{array}$ & \\
\hline
\end{tabular}

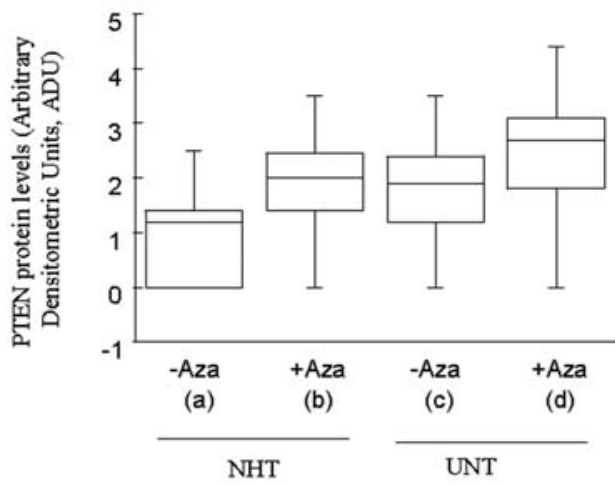

Figure 4. Effects of $1.0 \mathrm{mM}$ azacitidine (Aza) on mRNA and protein PTEN expression in cultures derived from untreated (UNT) or bicalutamide-treated patients in neoadjuvant regimen (NHT). (A) Summary of results showing the significativity of comparisons performed by Chi-square test. (B) Densitometric analysis of gels and definition of arbitrary densitometric units as the densitometric values of PTEN compared vs. a standard extract obtained from 22rv1 cells and statistical evaluations using Tukey's all pairs comparison analysis. d vs. a, Mean difference of 1.53462 , lq of 7.564 , P $<0.0001$ and 95\% CL ranged between 0.78443 and 2.2848. d vs. c, Mean difference of 0.808696 , lql of $3.8355, \mathrm{P}=0.039$ and $95 \% \mathrm{CL}$ ranged between 0.029077 and 1.5883 . d vs. b, Mean difference of 0.599807 , lql of $3.055, P=0.1419$ and $95 \% C L$ ranged between -0.13038 and 1.37 . b vs. a, Mean difference of 0.914815 , |ql of $4.701, P=0.0068$ and $95 \% \mathrm{CL}$ ranged between 0.19526 and 1.6344 . b vs. c, Mean difference of 0.188889 , lql of $0.931, \mathrm{P}=0.9124$ and a $95 \% \mathrm{CL}$ ranged between -0.5613 and 0.93908 . c vs. a, Mean difference of 0.785926 , lql of $3.578, \mathrm{P}=0.0416$ and a $95 \% \mathrm{CL}$ ranged between -0.024262 and 1.4961 .

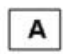

\begin{tabular}{|c|c|c|c|c|c|c|}
\hline \multirow{2}{*}{} & \multicolumn{2}{|c|}{$\begin{array}{c}\text { PTEN mRNA } \\
\text { positive }\end{array}$} & & \multicolumn{2}{c|}{$\begin{array}{c}\text { PTEN protein } \\
\text { positive }\end{array}$} & \\
\cline { 2 - 7 } & -VPA & +VPA & P value & -VPA & +VPA & P value \\
\hline UNT & $18 / 23$ & $18 / 23$ & 1.000 & $17 / 23$ & $19 / 23$ & 0.721 \\
& $(78.3 \%)$ & $(78.3 \%)$ & NS & $(75.9)$ & $(82.6 \%)$ & NS \\
\hline NHT & $11 / 27$ & $8 / 27$ & 0.569 & $10 / 27$ & $19 / 27$ & 0.029 \\
& $(40.7 \%)$ & $(29.6 \%)$ & NS & $(37 \%)$ & $(70.4 \%)$ & \\
\hline P value & 0.258 & 0.756 & & 0.020 & 0.498 & \\
& NS & NS & & & NS & \\
\hline
\end{tabular}

B

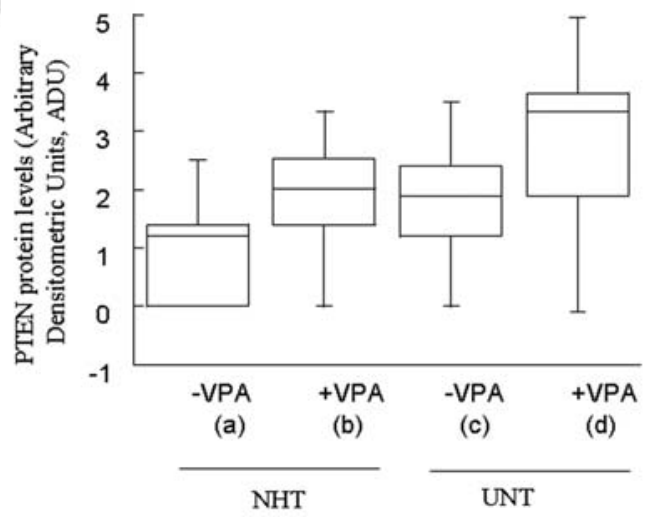

Figure 5. Effects of $1.0 \mathrm{mM}$ valproic acid (VPA) on mRNA and protein PTEN expression in cultures derived from untreated (UNT) or bicalutamidetreated patients in neoadjuvant regimen (NHT). (A) Summary of results showing the significativity of comparisons performed by Chi-square test. (B) Densitometric analysis of gels and definition of arbitrary densitometric units as the densitometric values of PTEN compared vs. a standard extract obtained from 22rv1 cells and statistical evaluations using Tukey's all pairs comparison analysis. d vs. a, Mean differences of 2.144561, lql of 11.424, $\mathrm{P}<0.0001$ and $95 \% \mathrm{CL}$ ranged between 0.243371 and 2.8224. $\mathrm{d}$ vs. c, Mean differences of 1.543452 , Iql of $7.856, \mathrm{P}<0.0001$ and $95 \% \mathrm{CL}$ ranged between 0.029077 and 2.4775. d vs b, Mean differences of 1.324663, lql of 7.187, $\mathrm{P}<0.0001$ and a $95 \% \mathrm{CL}$ ranged between -0.13038 and 1.37 . b vs. a, Mean differences of 0.997856 , lql of $5.123, \mathrm{P}=0.0025$ and a $95 \% \mathrm{CL}$ ranged between 0.19526 and 1.9457 . b vs. c, Mean differences of 0.146783 , lql of $0.976, \mathrm{P}=0.9874$ and a $95 \% \mathrm{CL}$ ranged between -0.5613 and 0.9390 . c vs. a, Mean differences of 0.785926 , lql of $3.578, \mathrm{P}=0.0416$ and a $95 \% \mathrm{CL}$ ranged between -0.024262 to 1.4961 .

to maintain elevated the basal levels of PTEN protein in primary cultures and in 22rv1 cells used as controls (Fig. 3) showing additive effects with VPA. These results suggest that the PTEN protein levels are modulated by proteasomedependent mechanisms.

PTEN expression and effects of neoadjuvant hormone bicalutamide-based therapy. Grouping prostate cancer cell primary cultures in those derived from naive prostate cancer patients (23 pts) and those derived from neoadjuvant hormone therapy (NHT)-treated patients (27 pts) we found that PTEN protein loss (Fig. 4A) were higher in the later group [17/27 (63\%) vs. 6/23 (26.1\%), P=0.020]. Parallely 5/23 (21.7\%) cultures from untreated patient group resulted negative in RT-PCR determination whereas 11/27 (40.7\%) cultures derived from NHT patient group were negative for mRNA. Thus we performed a densitometric analysis and defined arbitrary densitometric units as the densitometric values of PTEN compared vs. a standard extract obtained from 22rv1 
A

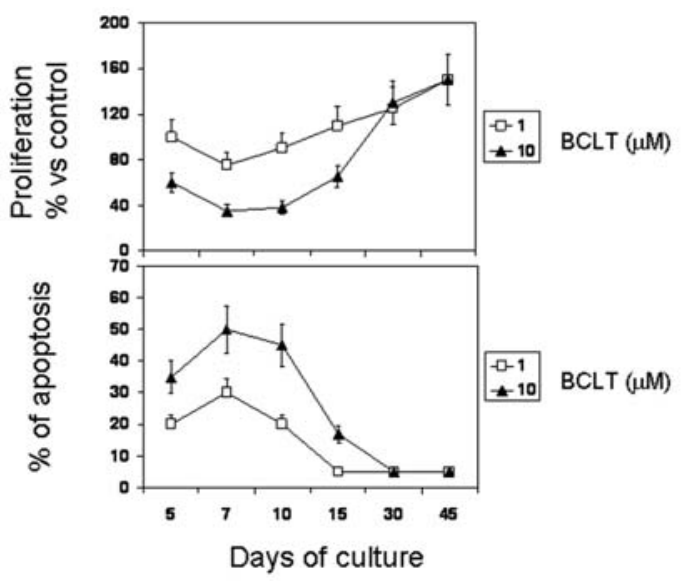

C

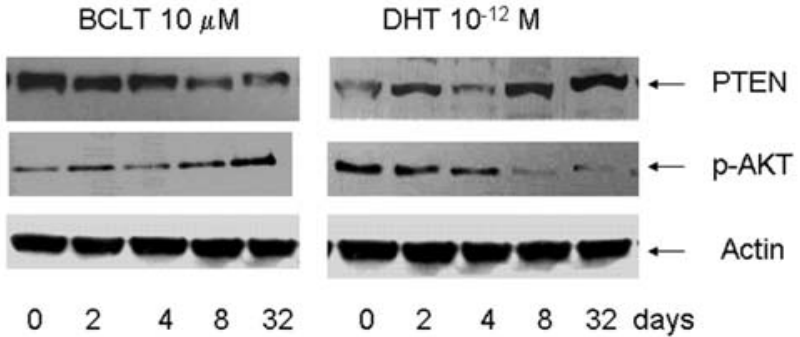

Figure 6. In vitro effects of bicalutamide on cell proliferation (A), apoptosis (B) and PTEN protein expression (C) in 22rv1 cells. (A) We analyzed the percentage of cell proliferation measured as percentage of cells vs. untreated controls at different days of culture in presence of 1.0 and $10.0 \mu \mathrm{M}$ bicalutamide (BCLT). (B) Percent of apoptotic cells was considered at different times of culture in presence of BCLT. BCLT resistant cells (BCLTR) develop during the culture in presence of 1.0 and $10.0 \mu \mathrm{M}$ BCLT and these cells maintain insensitivity vs. BCLT and DHT, BCLT and physiological concentrations of DHT maintain low and high, respectively, the levels of PTEN in a time-dependent manner. This is associated to increased Akt activity. Each lane show the PTEN and p-Akt protein expression from $40 \mu \mathrm{g}$ of protein.

cells. However, the densitometric amount of PTEN measured in untreated (UNT) patient group was not statistically higher $(\mathrm{P}=0.0616)$ when compared to NHT group (Fig. 4B). After treatment with $1 \mathrm{mM}$ azacitidine (Fig. 1), although PTEN expression was significantly increased in all PTEN-positive cultures, 4/6 (66.7\%) and 2/5 (40\%) cultures with low levels of PTEN protein and mRNA resulted once again PTENnegative in UNT group whereas $12 / 17(70.6 \%)$ and $8 / 11$ (72.7\%) cultures with low levels of PTEN protein and mRNA resulted once again PTEN-negative in NHT group. The percentage of PTEN-positive cultures after azacitidine treatment was not significant comparing UNT and NHT groups (Fig. 4A) although in NHT group the percentage of PTEN-negative cultures was almost halved (63 vs. 37\%). However, when we analyzed the densitometric amount of PTEN protein we found that PTEN expression was statistically higher after $1 \mathrm{mM}$ azacitidine treatment $(\mathrm{P}=0.039$ and $\mathrm{P}=0.0068$ both in UNT and NHT groups, respectively, Fig. 4B). Next we analyzed the effects of valproic acid on PTEN expression. In Fig. 5A we show that the perecentage of cultures with low or absent PTEN protein and mRNA expression were increased after VPA treatment also if this increment was statistically significant only in NHT group $(\mathrm{P}=0.029)$. The effects of VPA were more evident when we consider protein densitometric determinations (Fig. 5B) where PTEN levels were statistically higher both in UNT $(\mathrm{P}=0.035)$ and NHT $(\mathrm{P}<0.001)$ group.

Androgen modulation by PTEN expression. To obtain further demonstration of the role of anti-hormone therapy in the modulation of PTEN expression we cultured the PTEN- and AR-positive prostate cancer cell line, 22rv1, in presence or not of DHT or in presence of bicalutamide (casodex). In Fig. 6 we demonstrated that during the prolonged treatment with 1 and $10 \mu \mathrm{M}$ bicalutamide the antiproliferative (Fig. 6A) and pro-apoptotic (Fig. 6B) effects of bicalutamide were significatively reduced and after 60 days of cultures 22rv1 cells were insensitive to bicalutamide. Parallely, bicalutamide significantly down-modulated PTEN expression in a timedependent manner (Fig. 6C). As control, 22rv1 cells were cultured in presence of physiological concnetrations of DHT. In these condition the expression of PTEN was increased. This is also associated to increased phosphorylation (and thus activation) of Akt.

\section{Discussion}

The behavior of many neoplasms appears to be correlated with the expression of positive (worse prognosis) or negative (better prognosis) regulators of the PI3K/Akt signaling pathway. PTEN has been found deleted in a substantial fraction of cancers. Amplification and overexpression of Akt is frequently observed in solid cancer including prostate cancer (30-33). Moreover, recent studies suggest that the dosage of PTEN in prostatic lesions is directly correlated to $\mathrm{PCa}$ progression, incidence, and overall biology (5). Strengthening this argument are other studies stating that prolonged androgen-ablation therapy can lead to heightened levels of PI3K-signaling activity in PCa cells $(24,34)$. Consequently, efforts to regulate signals transduced through the PI3K pathway may provide therapeutic insight regarding progression and control of the disease. We have previously demonstrated that in vitro and in LuCaP35 xenograft in vivo experiments PTEN levels were regulated by androgen/antiandrogens (24). In vitro experiments performed on PTEN-positive ARpositive PCa cell lines indicated that PTEN expression was maintained at elevated levels in long-term androgen treatment whereas these levels were very low after long-term treatment with bicalutamide. The concomitant increament in the EGFR and Her2 expression synergizes with the reduction of PTEN in the upmodulation of Akt activity. Further we have previously demonstrated that the EGFR inhibitor, gefitinib, is able to synergize with BCLT in AR-positive cell lines in vitro $(35,36)$ and that effectiveness of this treatment regimens was modulated by PTEN/Akt activity. In addition we have also demonstrated that inhibition of PI3K-dependent signaling alone induces proliferative arrest (26). The modulation of DNA methylatrasferase as well as histone acetylation/ deacetylation activities represents a central mechanism for the control of gene expression and we observed in this study that the demethylating agent 5-azacitidine increases the expression of PTEN in PTEN-positive prostate cancer cells and induces the expression of PTEN in $~ 50 \%$ of PTENnegative prostate cancer cells. The induction of PTEN 
expression, considering the mean difference in a $95 \%$ confidence limit by Tukey's all-pairs comparison, is statistically higher in prostate cancer primary cultures derived from patients who undergone neoadjuvant bicalutamidebased anti-hormone therapy respect to those observed in cultured derived from untreated patients suggesting that increased DNMT activity can be observed during bicalutamide treatment. We observed that DNMT1, DNMT3a and DNMT3b (unpublished data) expression was increased in tumors after NHT and in AR- and PTEN-positive 22rv1 cells in vitro during bicalutamide treatment.

In addition we observed also that the pan HDAC inhibitor, valproic acid (VPA) increased PTEN protein expression only in true PTEN-positive cultures. Also in this case the induction of PTEN expression is statistically higher in prostate cancer primary cultures derived from patients who undergone neoadjuvant bicalutamide-based anti-hormone therapy respect to those observed in cultured derived from untreated patients suggesting that increased HDAC activity can be observed during bicalutamide treatment. The induction of PTEN by VPA could potenziate chemotherapy efficacy in prostate cancer after HRP development and this is in agreement with a recent study in which histone deacetylase inhibitor, trichostatin potentiates doxorubicin-induced apoptosis by upregulating PTEN expression (37). We demonstrated also that the inhibition of the proteasome with 17 AAG was able to maintain elevated the basal levels of PTEN protein showing additive effects with FK228 but not with VPA. It has been recently demonstrated that PTEN ubiquitization/deubiquitinylation and intracellular trafficking modulate its function (38). Our results indicated that PTEN inactivation in prostate cancer is both a genetic (mutations or PTEN gene deletion) and an epigenetic (gene methylation and protein ubiquitinization and degradation) event. The first seems is independent to antiandrogenic therapy whereas the second is increased after the antiandrogenic therapy with bicalutamide. In addition, our study demonstrates that epigenetic drugs can upmodulate PTEN expression and thus reduce Akt activity to enhance the efficacy of hormone therapy and chemotherapy. Further combination experiments should be performed to validate epigenetic therapy as useful therapeutic tool in the treatment of prostate cancer.

\section{References}

1. Wellington K and Keam SJ: Spotlight on bicalutamide $150 \mathrm{mg}$ in the treatment of locally advanced prostate cancer. Drugs Aging 24: 169, 2007.

2. Wu X, Senechal K, Neshat MS, Whang YE and Sawyers CL: The PTEN/MMAC1 tumor suppressor phosphatase functions as a negative regulator of the phosphoinositide 3-kinase/Akt pathway. Proc Natl Acad Sci USA 95: 15587, 1998.

3. Bertram J, Peacock JW, Fazli L, Mui AL, Chung SW, Cox ME, Monia B, Gleave ME and Ong CJ: Loss of PTEN is associated with progression to androgen independence. Prostate 66: 895-902, 2006.

4. Deocampo ND, Huang $\mathrm{H}$ and Tindall DJ: The role of PTEN in the progression and survival of prostate cancer. Minerva Endocrinol 28: 145-153, 2003.

5. Cansino Alcaide JR and Martinez-Pineiro L: Molecular biology in prostate cancer. Clin Transl Oncol 8: 148-152, 2006.

6. Trotman LC, Niki M, Dotan ZA, et al: Pten dose dictates cancer progression in the prostate. PLoS Biol 1: E59, 2003

7. Wang S, Gao J, Lei Q, et al: Prostate-specific deletion of the murine Pten tumor suppressor gene leads to metastatic prostate cancer. Cancer Cell 4: 209-221, 2003.
8. Ma X, Ziel-van der Made AC, Autar B, et al: Targeted biallelic inactivation of Pten in the mouse prostate leads to prostate cancer accompanied by increased epithelial cell proliferation but not by reduced apoptosis. Cancer Res 65: 5730-5739, 2005.

9. Stambolic V, Tsao MS, Macpherson D, Suzuki A, Chapman WB and Mak TW: High incidence of breast and endometrial neoplasia resembling human Cowden syndrome in pten + /mice. Cancer Res 60: 3605-3611, 2000.

10. Podsypanina K, Ellenson LH, Nemes A, Gu J, Tamura M, Yamada KM, Cordon-Cardo C, Catoretti G, Fisher PE and Parsons R: Mutation of Pten/Mmac1 in mice causes neoplasia in multiple organ systems. Proc Natl Acad Sci USA 96: 1563-1568, 1999.

11. Yilmaz OH, Valdez R, Theisen BK, Guo W, Ferguson DO, $\mathrm{Wu} \mathrm{H}$ and Morrison SJ: Pten dependence distinguishes haematopoietic stem cells from leukaemia-initiating cells. Nature 441: 475-482, 2006.

12. Freeman D, Lesche R, Kertesz N, et al: Genetic background controls tumor development in PTEN-deficient mice. Cancer Res 66: 6492-6496, 2006.

13. Di Cristofano A, Pesce B, Cordon-Cardo C and Pandolfi PP: Pten is essential for embryonic development and tumour suppression. Nat Genet 19: 348-355, 1998.

14. Roy-Burman P, Wu H, Powell WC, Hagenkord J and Cohen MB: Genetically defined mouse models that mimic natural aspects of human prostate cancer development. Endocr Relat Cancer 11: 225-254, 2004.

15. Jiao J, Wang S, Qiao R, Vivanco I, Watson PA, Sawyers CL and $\mathrm{Wu} \mathrm{H}$ : Murine cell lines derived from Pten null prostate cancer show the critical role of PTEN in hormone refractory prostate cancer development. Cancer Res 67: 6083-6091, 2007.

16. Davies MA, Kim SJ, Parikh NU, Dong Z, Bucana CD and Gallick GE: Adenoviral-mediated expression of MMAC/PTEN inhibits proliferation and metastasis of human prostate cancer cells. Clin Cancer Res 8: 1904-1914, 2002.

17. Zhao H, Dupont J, Yakar S, Karas M and LeRoith D: PTEN inhibits cell proliferation and induces apoptosis by downregulating cell surface IGF-IR expression in prostate cancer cells. Oncogene 23: 786-794, 2004.

18. Whang YE, Wu X, Suzuki H, Reiter RE, Tran C, Vessella RL, Said JW, Isaacs WB and Sawyers CL: Inactivation of the tumor suppressor PTEN/MMAC1 in advanced human prostate cancer through loss of expression. Proc Natl Acad Sci USA 95: 5246-5250, 1998.

19. Hermans KG, van Alewijk DC, Veltman JA, van Weerden W, van Kessel AG and Trapman J: Loss of a small region around the PTEN locus is a major chromosome 10 alteration in prostate cancer xenografts and cell lines. Genes Chromosomes Cancer 39: 171-184, 2004.

20. Verhagen PC, van Duijn PW, Hermans KG, Looijenga LH, van Gurp RJ, Stoop H, van der Kwast TH and Trapman J: The PTEN gene in locally progressive prostate cancer is preferentially inactivated by bi-allelic gene deletion. J Pathol 208: 699-707, 2006.

21. Bedolla R, Prihoda TJ, Kreisberg JI, Malik SN, Krishnegowda NK, Troyer DA and Ghosh PM: Determining risk of biochemical recurrence in prostate cancer by immunohistochemical detection of PTEN expression and Akt activation. Clin Cancer Res 13: 3860-3867, 2007.

22. El Sheikh SS, Romanska HM, Abel P, Domin J and Lalani el-N: Predictive value of PTEN and AR coexpression of sustained responsiveness to hormonal therapy in prostate cancer - a pilot study. Neoplasia 10: 949-953, 2008.

23. Wang Y, Kreisberg JI and Ghosh PM: Cross-talk between the androgen receptor and the phosphatidylinositol 3-kinase/Akt pathway in prostate cancer. Curr Cancer Drug Targets 7: 591-604, 2007.

24. Festuccia C, Gravina GL, Muzi P, Pomante R, Ventura L, Vessella RL, Vicentini $\mathrm{C}$ and Bologna $\mathrm{M}$ : Bicalutamide increases phospho-Akt levels through Her2 in patients with prostate cancer. Endocr Relat Cancer 14: 601-611, 2007.

25. Chinni SR and Sarkar FH: Akt inactivation is a key event in indole-3-carbinol-induced apoptosis in PC-3 cells. Clin Cancer Res 8: 1228-1236, 2002.

26. Festuccia C, Gravina GL, Muzi P, Millimaggi D, Dolo V, Vicentini $\mathrm{C}$ and Bologna $\mathrm{M}$ : Akt down-modulation induces apoptosis of human prostate cancer cells and synergizes with EGFR tyrosine kinase inhibitors. Prostate 68: 965-974, 2008.

27. Sramkoski RM, Pretlow TG II, Giaconia JM, Pretlow TP, Schwartz S, Sy MS, Marengo SR, Rhim JS, Zhang D and Jacobberger JW: A new human prostate carcinoma cell line, 22Rv1. In Vitro Cell Dev Biol Anim 35: 403-409, 1999. 
28. Festuccia C, Gravina GL, Muzi P, Pomante R, Angelucci A, Vicentini $\mathrm{C}$ and Bologna $\mathrm{M}$ : Effects of dutasteride on prostate carcinoma primary cultures: a comparative study with finasteride and MK386. J Urol 180: 367-372, 2008.

29. Festuccia C, Angelucci A, Gravina GL, Muzi P, Miano R, Vicentini $\mathrm{C}$ and Bologna $\mathrm{M}$ : Epithelial and prostatic marker expression in short-term primary cultures of human prostate tissue samples. Int J Oncol 26: 1353-1362, 2005.

30. Graff JR, Konicek BW, McNulty AM, Wang Z, Houck K, Allen S, Paul JD, Hbaiu A, Goode RG, Sandusky GE, Vessella RL and Neubauer BL: Increased AKT activity contributes to prostate cancer progression by dramatically accelerating prostate tumor growth and diminishing p27Kip1 expression. J Biol Chem 275: 24500-24505, 2000

31. Ayala G, Thompson T, Yang G, Frolov A, Li R, Scardino P, Ohori M, Wheeler T and Harper W: High levels of phosphorylated form of Akt-1 in prostate cancer and nonneoplastic prostate tissues are strong predictors of biochemical recurrence. Clin Cancer Res 10: 6572-6578, 2004.

32. Uzgare AR and Isaacs JT: Enhanced redundancy in Akt and mitogen-activated protein kinase-induced survival of malignant versus normal prostate epithelial cells. Cancer Res 64: 6190-6199, 2004.

33. Shukla S, Maclennan GT, Marengo SR, Resnick MI and Gupta S: Constitutive activation of P I3 K-Akt and NF-kappaB during prostate cancer progression in autochthonous transgenic mouse model. Prostate 64: 224-239, 2005.
34. Murillo H, Huang H, Schmidt LJ, Smith DI and Tindall DJ: Role of PI3K signaling in survival and progression of $\mathrm{LNCaP}$ prostate cancer cells to the androgen refractory state. Endocrinology 142: 4795-4805, 2001.

35. Festuccia C, Gravina GL, Muzi P, Biordi L, Ronchi P, Martella O, Vicentini $\mathrm{C}$ and Bologna M: Gefitinib and bicalutamide show synergistic effects in primary cultures of prostate cancer derived from androgen-dependent naive patients. Oncol Rep 18: 1321-1327, 2007.

36. Festuccia C, Gravina GL, Angelucci A, Millimaggi D, Muzi P, Vicentini C and Bologna M: Additive antitumor effects of the epidermal growth factor receptor tyrosine kinase inhibitor, gefitinib (Iressa), and the nonsteroidal antiandrogen, bicalutamide (Casodex), in prostate cancer cells in vitro. Int $\mathrm{J}$ Cancer 115: 630-640, 2005

37. Pan L, Lu J, Wang X, Han L, Zhang Y, Han S and Huang B: Histone deacetylase inhibitor trichostatin a potentiates doxorubicin-induced apoptosis by up-regulating PTEN expression. Cancer 109: 1676-1688, 2007.

38. Song MS, Salmena L, Carracedo A, Egia A, Lo-Coco F, Teruya-Feldstein J and Pandolfi PP: The deubiquitinylation and localization of PTEN are regulated by a HAUSP-PML network. Nature 455: 813-817, 2008. 